\title{
Scaling up: Assessing social impacts at the macro-scale
}

\author{
Jacki Schirmer * \\ Fenner School of Environment and Society, Australian National University, Canberra, Australia \\ Cooperative Research Centre for Forestry, Hobart, Australia
}

\section{A R T I C L E I N F O}

\section{Article history:}

Received 26 July 2010

Received in revised form 16 December 2010

Accepted 19 December 2010

Available online $\mathrm{xxxx}$

\section{Keywords:}

Social impact assessment

Social change

Community impact

Scale

\begin{abstract}
A B S T R A C T
Social impacts occur at various scales, from the micro-scale of the individual to the macro-scale of the community. Identifying the macro-scale social changes that results from an impacting event is a common goal of social impact assessment (SIA), but is challenging as multiple factors simultaneously influence social trends at any given time, and there are usually only a small number of cases available for examination. While some methods have been proposed for establishing the contribution of an impacting event to macro-scale social change, they remain relatively untested. This paper critically reviews methods recommended to assess macro-scale social impacts, and proposes and demonstrates a new approach. The 'scaling up' method involves developing a chain of logic linking change at the individual/site scale to the community scale. It enables a more problematised assessment of the likely contribution of an impacting event to macro-scale social change than previous approaches. The use of this approach in a recent study of change in dairy farming in south east Australia is described.
\end{abstract}

(c) 2010 Elsevier Inc. All rights reserved.

\section{Introduction}

Social impacts occur in many and varied forms, and can be explored at different scales. The impact of changed employment opportunities, for example, may be examined at the scale of the individual and family whose lives are profoundly affected by job loss, through to its impacts on social capital and opportunity across an entire community. Each is important for understanding the social impacts of the change, and most social impact assessment (SIA) literature encourages practitioners to consider and assess social impacts at a range of scales (van Schooten et al., 2003; Burdge, 2004).

Although most literature suggests assessing social impacts at varying scales, relatively little attention has been given to designing SIA methods that meet the unique needs of assessing impacts at different scales. This is a key gap, as the requirements of effective SIA vary depending on the scale being examined. At the micro-scale of the individual and family, a SIA must explore the ways an impacting event interacts with an individual's social circumstances and psychological outlook. At the community- or 'macro'-scale, considerations include the extent to which the impacting event triggers flow-on change beyond the individuals it directly affects, and interacts with social conditions and trends to result in a unique set of outcomes for the community involved. Successfully assessing social impacts at the macro-scale is particularly challenging. Human communities are in a state of constant change, and as such there is a real danger of making

\footnotetext{
* Fenner School of Environment and Society, Building 48, Australian Nationa University, ACT 0200, Australia. Tel.: +61 26125 2737; fax: +61261250746.

E-mail address: jacki.schirmer@anu.edu.au.
}

false causal inferences in macro-scale SIAs: focusing on the implications of a single impacting event can lead to the assumption that it is the primary agent of change in a community, when in reality it will be one amongst many influences (Geddes, 1990).

This paper reviews the comparative methods commonly advocated for identifying macro-scale social impacts, where the macro-scale is defined as a region or community, as opposed to the micro-scale of the individual and family, or meso-scale of particular groups within a community. A new 'scaling up' approach is then proposed that enables improved analysis of the interaction of an impacting event and other trends at the macro-scale, and therefore better identification of the outcomes of an impacting event in different social circumstances. Recognising that SIA is best considered as a process rather than a technical research project (ICGPSIA, 2003; Vanclay, 2003), the scalingup approach is designed to be embedded in participatory SIA processes, using participatory data collection and analysis combined with a rigorous technical approach to assessing the contribution of the impacting event to social change. The use of both comparative methods and the scaling-up framework in a recent SIA examining dairy farming in south east Australia is described, highlighting some of the challenges inherent in both approaches.

Throughout this paper, I primarily focus on identifying the social change processes associated with an impacting event. Less attention is given to the equally important issue of identifying how these social changes are experienced by different individuals, groups and communities - or in other words to the impacts of social changes. Drawing on Slootweg et al. (2001) and Vanclay (2002), I therefore use the term 'social change' or 'social change process' rather than 'social impact' throughout the remainder of the paper, with the term 'impact' 
used only when referring to how people experience a social change. The term 'community', meanwhile, is used to refer to a large group of people, often living in the same geographic region, who have shared social relationships.

\section{Identifying social changes at the macro-scale}

A number of methods are suggested in SIA literature for identifying macro-scale social changes resulting from an impacting event, although many of these are applied across a range of scales. Baseline analysis, a mainstay of SIA, is a key tool used for assessing macro-scale social change. Baseline analysis typically involves profiling key social characteristics and trends in a given community prior to a change being implemented, with this analysis forming the basis for both initial prediction of potential social changes, and later monitoring of the social changes resulting from an impacting event (Wolf, 1983; TICGPSIA, 2003; Vanclay, 2003; Burdge, 2004; Ross and McGee, 2006). Although intended to support analysis of the social changes resulting from an impacting event, there is surprisingly little guidance on how to go about this in the SIA literature beyond various recommendations of variables to include in the baseline profile (see for example Bureau of Rural Sciences, 2005; Twigg, 2007). This likely reflects the diverse disciplines often drawn on in SIA, each with its own approach to uncovering impacts; but also reflects a lack of methodologies developed specifically for SIA.

Despite this general lack of guidance, some approaches have been proposed for uncovering relationships between impacting events and social change. These typically involve some form of comparative analysis. The specific types of comparison recommended usually involve either time-based comparison, comparison to an average, or comparison to other cases (usually other geographically bound communities). Although sometimes recommended for different stages of SIA, such as profiling versus monitoring and evaluation (Taylor et al., 2003).

In time-based comparisons, socio-economic characteristics and trends in a community are compared at two points in time - before occurrence of an impacting event, and after it occurs (Indhapanya et al., 1999; Taylor et al., 2003). The assumption is that differences observed pre- and post-implementation will be causally related to the impacting event, and that other factors leading to socio-economic change remain stable during the period examined. In reality, social and economic trends are unlikely to stay stable over time (Twigg, 2007).

Alternatively, social characteristics and trends in the potentially impacted community may be compared to trends for the larger region in which that community is situated, in order to understand in what ways the impacted community differs to the 'average'. In ex-ante SIA, this approach is used to identify characteristics that may affect how a community responds to the impacting event. In ex-post SIA, if the impacted community is found to have changed in different ways to the average for the larger region, this is considered an indication that the impacting event may have contributed to the difference. This 'comparison to averages' approach is commonly used in current SIAs, particularly as part of assessing baseline conditions (see for example Fortin and Gagnon, 1999; Petajarjarvi, 2005; Woodside Energy, 2007). This approach assumes that the larger region will have social characteristics relatively similar to those of the impacted community located within it, so that observing and comparing social trends in both will reveal something about the influence of the impacting event.

A third approach is to seek comparison cases that are similar to the impacted community in most respects but the impacting event (Becker et al., 2004; Burdge and Johnson, 2004). The comparison communities are not necessarily located in close geographic or temporal proximity to the impacted community, but are similar in terms of key socio-economic characteristics and trends. This has most commonly been proposed for monitoring and evaluating post- implementation impacts, with the diachronic model developed by Burdge (1987) and subsequently Taylor et al. (2004) suggesting that ex-post impacts should be assessed by comparing the impacted community to a 'control' community. This approach requires identification of cases that are adequately similar.

Finally, the impacted community may be compared to others where a similar impacting event has occurred. This is most commonly recommended as part of ex-ante SIA, with the diachronic model recommending examination of previous cases of impact in order to inform predictions made about the soon-to-be impacted community (Burdge, 1987; Taylor et al., 2003). However, this concept can be extended to compare multiple communities in which the magnitude of the impacting event differs, in order to understand how its impacts vary in different circumstances.

These comparative approaches have a relatively similar underlying logic, albeit applied in different ways: that by comparing cases involving the presence and absence (or the presence to differing degrees) of the impacting event, it is possible to isolate its likely or actual influences on a community; and that macro-scale impacts can be identified based on comparison of macro-scale trends in different communities or time periods.

This requires that the times or communities compared are similar in all respects other than the impacting event, something that is difficult to achieve in practice (Teigland, 1999; Asselin and Parkins, 2009). In reality, social trends are highly unstable over time, and it is difficult to find cases that are identical in all respects but the impacting event (Burdge and Johnson, 2004). Because of this, comparative approaches have high potential for false inference: it is not safe to assume that social changes present only in association with the dependent variable (the impacting event) are causally linked to it, as a range of other factors will be influencing social changes in both the impacted and comparison community (Geddes, 1990).

In quantitative studies, these problems would be addressed by increasing the number of cases studied and using methods such as regression analysis to identify the extent to which the presence of the impacting event explains social change. However, this is not generally feasible in SIA, where a lack of readily identifiable comparable cases means there are usually a small number available to compare (Taylor et al., 2003). The SIA practitioner has to achieve the best analysis possible with a small number of cases, typically requiring robust qualitative methods. Having only a small number of cases presents opportunities as well as challenges. In qualitative research, in-depth explanatory analysis is typically used to identify likely causal links between an event and its outcomes. This suggests the potential for an alternative to comparative approaches, which focuses on developing an explanatory logic linking the impacting event to particular types of social change, and identifying the likely contributions of other influences to social change occurring in an impacted community.

Fig. 1 proposes a framework that uses a 'scaling up' approach to develop this explanatory logic. Whereas comparative approaches involve analysis of macro-scale trends without explicitly linking them to micro-scale change, the scaling up framework assumes that macroscale impacts emerge from smaller scale change. Therefore, the first step of the scaling up framework involves analysis of the social changes resulting from an impacting event at the micro-scale of the individual, family or business. In the second step, these are 'scaled up' to identify what their contribution to macro-scale community trends would be in the absence of other social change. Finally, other influences on social trends are identified and the relative influence of these versus the impacting event identified, enabling an understanding of the contribution of the impacting event to overall social changes occurring in the community. In the model, each step is clearly situated within the broader social context, with socio-economic conditions in the region influencing how impacts are experienced at each scale.

The impacting event may be analysed at one or multiple individual sites, enabling an understanding of the differing nature of its impacts 


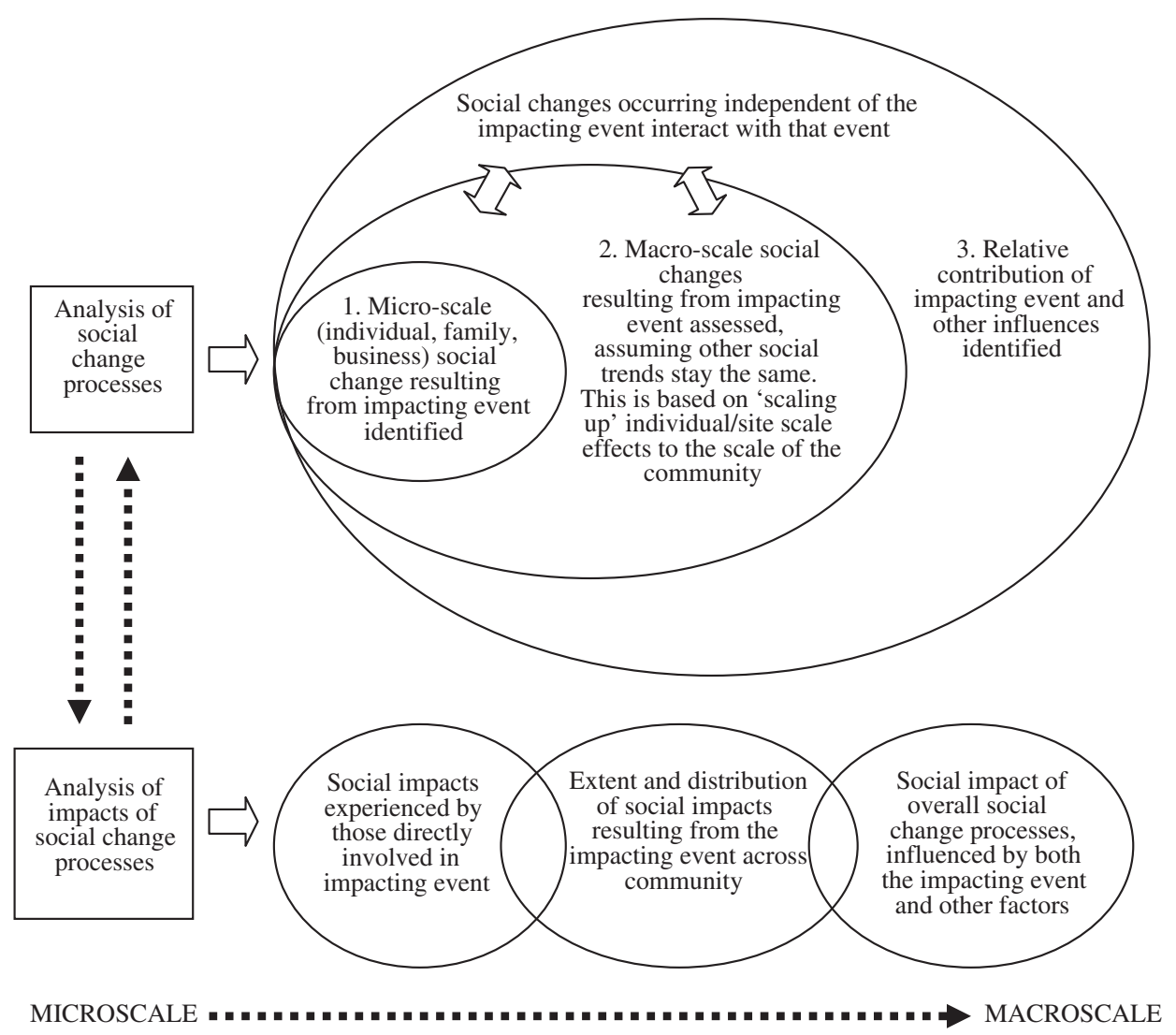

Fig. 1. The 'scaling up' model for assessing macro-scale social impacts.

in a range of localised circumstances. The 'scaling up' approach is compatible with utilising both qualitative and quantitative data, and can be used as part of participatory approaches to SIA, with stakeholder consultation a useful method for identifying both likely micro-scale social changes, and the various factors influencing social change at the macro-scale.

\section{Case study: change in the dairy farming industry in south east Australia}

Both comparative approaches and the scaling up framework were used to analyse social changes associated with change in dairy farming in south east Australia over 1991 to 2006. This ex-post SIA study enabled comparison of the usefulness and limitations of each approach in identifying social change associated with an impacting event.

\subsection{Case study background}

The study region, shown in Fig. 2, is a highly productive agricultural region known as the 'Green Triangle', located in southwest Victoria and south-east South Australia. Dairy farming is an important industry in this region, with $14.9 \%$ of Australia's dairy herd located in the region in 2006, as well as much of the nation's dairy manufacturing. Since dairy farming was first established in the mid nineteenth century, the industry has been characterised by ongoing change, and recent years have been no exception. Over 1991 to 2001, the dairy herd in the study region grew by $53.4 \%$ and milk production doubled, a result of technology changes enabling increased efficiency of production combined with growing demand for milk from the region's dairy processors. This was followed by a $7.4 \%$ decline in the region's dairy herd over 2001 to 2006, driven by changes including deregulation of the industry (Schirmer et al., 2008a).
Growth in dairy farming has been identified as one of the key land use changes leading to social change in the study region, most particularly in the recent 'Land Use Change' study examining change occurring on agricultural land in the region over 1991 to 2006 (Schirmer et al., 2008a). The early stages of this study documented a range of perceptions about the social impacts of changes to dairy farming. While many residents believe expansion of dairy farming is associated with maintenance of social capital and viability of rural communities at the macro-scale, not all share these views, as reported by Schirmer et al. (2008b) and Williams et al. (2008).

To help inform local discussions about the implications of change in the industry, an assessment of ex-post impacts was undertaken as part of latter stages of the 'Land Use Change' study to better understand what social changes are associated with change in dairy farming. While multiple socio-economic issues were analysed, only one is examined in this paper: the relationship between change in dairy farming, and change in the number of people living in rural areas of the study region over 1991 to 2006. Schirmer et al. (2008b) and Williams et al. (2008) identified that many local residents believed dairy farming expansion was associated with rural population growth (or at the least, slower decline). This rural population change was believed by residents to be a trigger for a cascade of further social change, including changes to the viability of local services and community groups, local social capital, and opportunities for and hence retention of young people in the community. Analysing this seemingly simple relationship provides an ideal case for comparing the effectiveness of comparative and scaling up methods in identifying the relationship between an impacting event (change in dairy farming) and social change (rural population growth or decline).

\subsection{Methods}

The study region covers a large geographic area incorporating multiple rural settlements and towns, which experienced a range of 


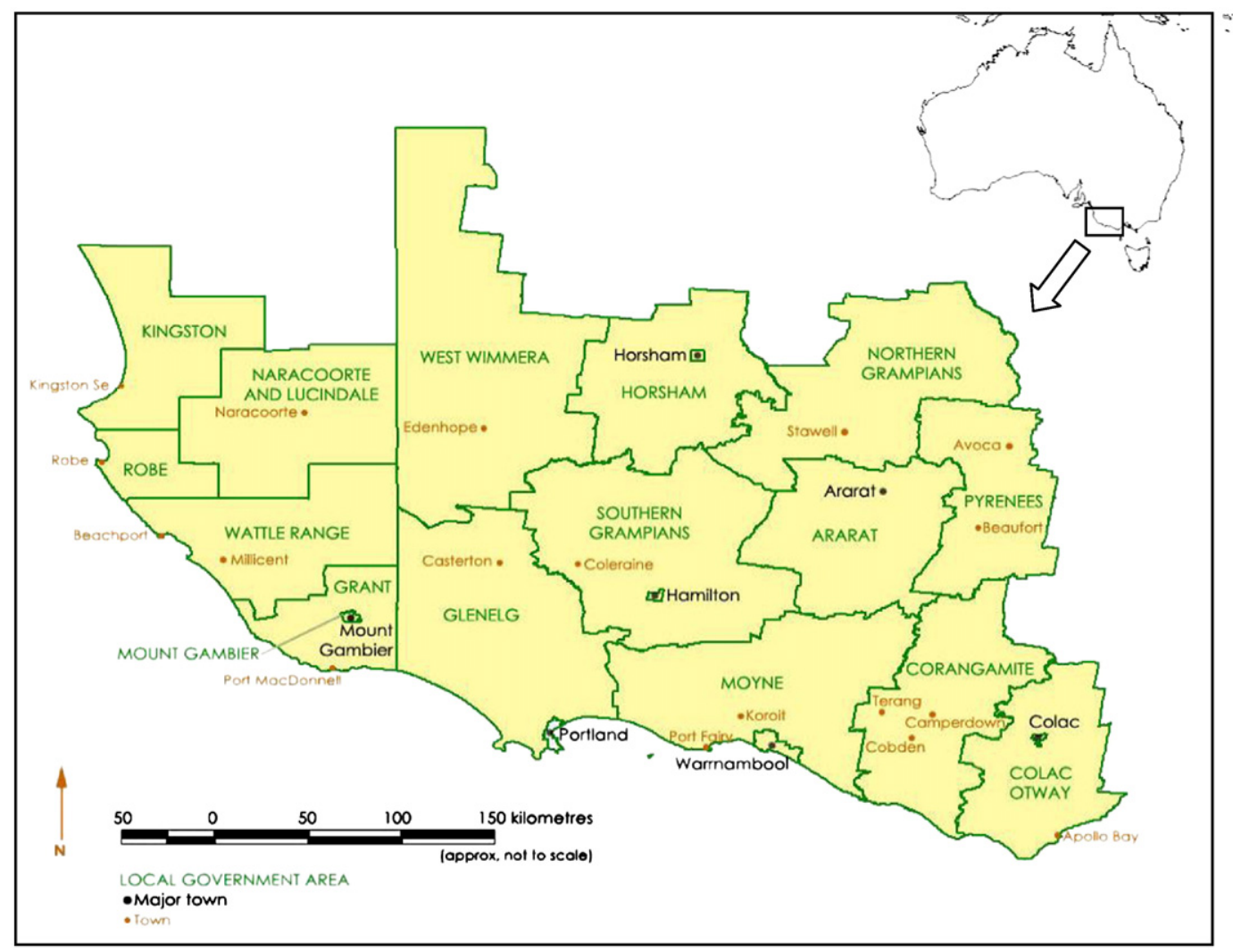

Fig. 2. Location of the 'Green Triangle' study region.

social and economic trends over 1991 to 2006. Rather than assume the study region formed a single case, the region was broken into multiple 'cases'. The ideal boundaries for a case were defined as being any community that was relatively bounded and experienced social trends distinct from those of neighbouring communities. As well as reducing the potential for a single case to include multiple communities experiencing differing social trends, breaking the region into multiple cases had the benefit of increasing the number of comparisons made, and enabling exploration of how different social contexts influence the relationship between dairy farming and rural population change.

The region was broken into multiple communities using an existing boundary, that of the 'Statistical Local Area' (SLA). The Australian Bureau of Statistics (ABS) splits local government areas into between one and three SLAs and reports statistics for each over time. SLA boundaries are usually based on historical shire boundaries, meaning that each SLA is relatively localised to a small geographic region with a specific and unique history that can be considered a unique 'community'. Local residents, when asked to describe their local communities, often described geographic regions that approximated SLA boundaries, supporting the use of this boundary. More pragmatically, longitudinal statistical data were available at the SLA scale.

The study region included 31 SLAs, whose boundaries are shown in Fig. 2. These were analysed to identify the different cases of dairy farming change in the region over 1991 to 2006. Dairy farming occurs primarily in the south of the region, with eight SLAs having a herd of over 15,000 cows in 2006, and relatively little dairy farming occurring in other SLAs. An SLA was only considered to have experienced significant change in dairy farming over time if two criteria were met: the SLA had experienced change of more than 10,000 cows in the dairy herd in a five year period during 1991 to 2006 , and more than $10 \%$ of their labour force was directly dependent on the dairy industry in 2006 (Table 1). These criteria were used as changes of smaller magnitude were unlikely to have an observable impact on socio-economic characteristics of an SLA, although they would undoubtedly have important impacts for the individuals involved. Based on these criteria, four SLAs were considered cases where dairy farming change may have observable impacts on macro-scale social characteristics: Corangamite South, Moyne South, Corangamite North and Moyne North West. This analysis was supported by discussion with local residents.

Having identified cases, statistical data were gathered identifying change in dairy farming, and in rural population, using data sources from the ABS Census of Population and Housing (rural population, dairy farming and dairy manufacturing employment figures), ABS Agricultural Census (dairy herd size data), and WestVic Dairy, the regional dairy research and development agency (milk production statistics).

A key challenge when using statistics produced for relatively small areas is identifying their validity and reliability for that community. To assess this, statistical data were initially summarised, and then analysed together with local experts in a series of focus groups. A 'local expert' was defined as a person with expert knowledge on their local community or the region as a whole. This expertise was not necessarily a result of particular types of professional work, but rather could be drawn from any of the different knowledges argued to be essential for social learning by Brown and Ritchie (2006), such as personal lived experience. Ten focus groups were held in eight locations, with a total of 66 people participating. Participants included local government councillors and planners, farmers and graziers, rural real estate and stock agents, members of local community groups and fire brigades, and local rural consultants and extension officers. Focus group sessions were held at a variety of times to enable participants to attend either an afternoon or evening session. Focus group participants were asked to discuss the reliability and validity of the data, the different factors they believed contributed to changes in rural population over time, and drivers and consequences of changes to dairy farming. After the focus group discussions, comparative analyses and the scaling up framework were used to explore likely relationships between dairy farming change and change in rural population. 
Table 1

Extent of and dependence on the dairy industry, by statistical local area.

\begin{tabular}{|c|c|c|c|c|c|c|}
\hline \multirow{2}{*}{$\begin{array}{l}\text { Statistical local } \\
\text { area }\end{array}$} & \multicolumn{4}{|c|}{ Number of cows } & \multirow{2}{*}{$\begin{array}{l}\% \text { labour } \\
\text { force in dairy } \\
\text { farming } 2006\end{array}$} & \multirow{2}{*}{$\begin{array}{l}\text { \% labour force in } \\
\text { dairy manufacturing } \\
2006\end{array}$} \\
\hline & 1991 & 1996 & 2001 & 2006 & & \\
\hline Corangamite South & 84,033 & 100,311 & 131,288 & 126,154 & 35.91 & 3.83 \\
\hline Moyne South & 42,122 & 35,946 & 76,088 & 87,983 & 17.50 & 3.84 \\
\hline Colac-Otway North & 45,662 & 45,063 & 55,020 & 49,947 & 18.64 & 3.04 \\
\hline Corangamite North & 30,714 & 38,426 & 48,935 & 42,715 & 12.14 & 2.40 \\
\hline Grant & 12,097 & 15,028 & 23,377 & 27,017 & 6.77 & 0.49 \\
\hline Moyne North-East & 9939 & 13,476 & 19,646 & 18,965 & 13.82 & 1.80 \\
\hline Moyne North-West & 23,120 & 51,712 & 34,102 & 18,222 & 9.96 & 1.59 \\
\hline Glenelg Heywood & 7279 & 9195 & 17,869 & 15,990 & 6.18 & 0.12 \\
\hline
\end{tabular}

Data source: ABS Agricultural Census, ABS Census of Population and Housing.

\subsection{Comparative approaches}

Data were analysed using three comparative approaches identified from the SIA literature: time-based comparisons, comparison to averages, and comparison to similar regions. When using each approach, the four cases of dairy farming change were compared to each other, enabling comparison of multiple communities in which the impacting event occurred.

\subsubsection{Time-based comparisons}

First, a time-based comparison was undertaken. In this type of longitudinal analysis, it is usually recommended that baseline trends be established for a period prior to the impacting event occurring, followed by examining whether and how the impacting event leads to a departure from the baseline (Bureau of Rural Sciences, 2005; Twigg, 2007). This assumes the impacting event occurs over a short space of time. Change in dairy farming, however, occurred incrementally and at varying rates over time. As such, there is no simple 'baseline' period during which little change occurred in dairy farming.

Therefore, rather than select a 'baseline' period, multiple timebased cases of differing types of change in the industry were identified. Dairy regions were classified by whether they experienced low, moderate or high expansion or decline in dairy herd size over the three five year periods between 1991 and 2006. Rural population change over each period was then compared to the rate and direction of change in dairy farming, to identify any correlations. Table 2 shows the rate of population change in each period, while Fig. 3 compares the rate of population change and rate of dairy farming change, irrespective of the time period, with each five year period considered an individual case.

Table 2

Comparison of rural population change in dairy farming SLAs and comparison regions.

\begin{tabular}{lccc}
\hline Region & \multicolumn{3}{c}{ Rural population change (\%) } \\
\cline { 2 - 4 } & $1991-1996$ & $1996-2001$ & $2001-2006$ \\
\hline Corangamite South & 5.91 & -4.49 & -2.18 \\
Moyne South & -4.75 & 0.17 & -1.03 \\
Corangamite North & -10.23 & -8.97 & -6.42 \\
Moyne North-West & -10.05 & -7.90 & -2.23 \\
Study region & -1.42 & -6.48 & -4.33 \\
Victoria & -1.95 & -8.65 & -3.46 \\
Geographically proximate SLAs (average) & -6.64 & -2.28 & -7.78 \\
Corangamite North comparison SLAs & -1.52 & -4.40 & -4.34 \\
$\quad$ (average) & & & \\
Corangamite South comparison SLAs & 3.14 & 6.63 & -5.54 \\
$\quad$ (average) & & & \\
Moyne South comparison SLAs (average) & 3.68 & 12.03 & 3.11 \\
Moyne North West comparison SLAs & -4.47 & -10.39 & -1.49 \\
$\quad$ (average) & & & \\
\hline
\end{tabular}

Data source: ABS Census of Population and Housing.

a Rural population is defined as the number of people living on rural properties or in settlements with fewer than 200 residents.
No clear relationship between rural population and change in dairy herd size is evident from the data when it is explored for a relationship between change in dairy farming and population. In general, rural population declined more in Corangamite North and Moyne North-West than the other two SLAs, irrespective of the rate or direction of change in dairy farming. For time-series comparisons to be more informative, further analysis is needed that controls for the other factors influencing population change; without this, it is not possible to isolate the extent to which dairy farming contributed to the variation in population trends observed. This type of additional analysis is not typically discussed in the SIA literature, but is a logical additional step to improve the usefulness of time series comparisons. An initial attempt to undertake this analysis was made. Factors other than change in dairy farming that potentially influenced population levels were identified in focus group discussions. This was followed by gathering available data on these factors, and attempting to analyse these data to 'control' for factors other than dairy farming. This approach was unsuccessful, for two reasons: few statistics were available for some variables considered important influences by focus group participants; and the small number of cases involved, and high number of variables influencing population, meant that the confidence intervals of any statistical analysis was so large as to render the outputs of the analysis relatively meaningless. A more qualitative exploration of the multiple factors influencing change was subsequently undertaken as part of applying the 'scaling up' framework, described in Section 3.4.

\subsubsection{Comparison to averages}

Change in rural population in the four dairy SLAs was next compared to the average for the study region as a whole (shown in Fig. 2), and the state of Victoria. This analysis was undertaken for 1996 to 2006, as some data for 1991 were inaccurate for the larger region and therefore could not be analysed.

Similar to the time-series comparison, rural population change in dairy regions was not consistently different to that in the broader region or state of Victoria as a whole - rural population declined less than average in the two southern dairy SLAs, more than average in Corangamite North, and either similarly to or more than average in Moyne North West, over 1996 to 2006 (Table 2). Similar to time series analysis, comparison to averages was uninformative unless accompanied by more exploration of the multiple factors leading to differing rates of change in rural population in each SLA versus the larger regions; this type of analysis was subject to the same limitations described in the previous section, but to a greater extent, as in larger regions it can be more difficult to identify the multiple factors likely to be influencing population change than in a smaller case study region.

\subsubsection{Comparison to similar regions (case-based comparison)}

Finally, comparison regions were selected that were more closely matched to the socioeconomic characteristics of each of the four dairy farming SLAs. Two types of comparison SLAs were selected: 


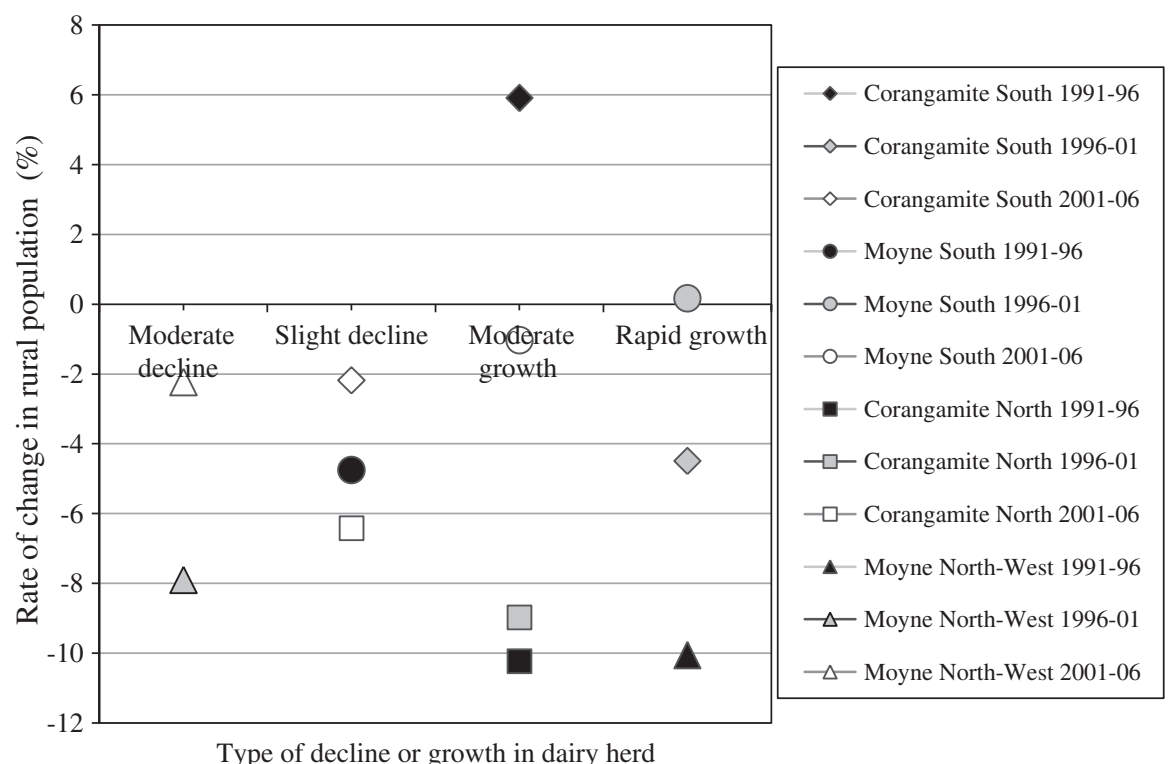

Fig. 3. Comparison of change in rural population and dairy herd size for individual SLAs, 1991 to 2006.

geographically proximate regions, which may be similar to the dairy regions as a result of their close proximity; and regions not located geographically adjacent to the dairy farming SLAs, but with similar characteristics.

The SLAs immediately to the north of the dairy farming SLAs ${ }^{1}$ were selected as the most appropriate geographically proximate regions to use as comparison cases as they were rural, whereas those to the east were relatively urbanised.

Selecting comparison cases that were not geographically proximate was more complex. Relatively little guidance is provided in the SIA literature on what makes two regions comparable, beyond Burdge and Johnson's (2004) suggestion, based on practical experience, to match regions based on social and demographic characteristics such as population size, age and gender structure, geographic area, the ratio of urban to rural population, agricultural production and the labour force.

For this study, regions were considered comparable if they were similar in terms of (a) key biophysical characteristics, (b) economic and population structure, and (c) indicators of adaptive capacity of the resident population. Biophysical characteristics are important predictors of some types of social change (Adger, 2000; Gallopin, 2006). For example, severe drought has led to considerable social change in some Australian regions in recent years, and so regions needed to have experienced similar patterns of drought to dairy regions to remove this as a confounding factor in the analysis. Economic and population structure are important, as there is considerable evidence suggesting that population and economic structure are reasonable predictors of population trajectory in rural Australia (Stimson et al., 2003; Maude, 2004; Hugo, 2005). Finally, the adaptive capacity of individuals and communities influences how they experience change. Factors influencing adaptive capacity may include access to social, human and economic capital, access to and ability to utilise information, and the policy and institutional environment, amongst others (Yohe and Tol, 2002; Brooks and Adger, 2004; Pelling and High, 2005; Smit and Wandel, 2006).

Bearing in mind Burdge and Johnson's (2004) caution that perfect comparability is an unattainable goal, and patterns of similarity a more realistic objective, these concepts were translated into relatively simple indicators: similarity was sought in population size and age

\footnotetext{
${ }^{1}$ Wattle Range East, Wattle Range West, Glenelg North, Southern Grampians Balance, Ararat and Pyrenees South.
}

structure, family structure, industry and economic diversity, labour force characteristics, educational attainment and household income levels.

A database of all rural Australian SLAs greater than 50 square kilometres in area, with a population of more than 50 people but less than 60,000 , was compiled. This created a total of 686 possible comparison SLAs across Australia. Cluster analysis was used to identify regions with similarity in the characteristics listed above in 1991, and in how they changed over 1991 to 1996 . The period of most rapid dairy farming change was 1996 to 2001 , and therefore the period prior to this - 1991 to 1996 - was the one in which cases needed to be as similar as possible. A $k$-means cluster analysis was used with 50 iterations to identify key clusters. The geographically proximate regions already selected as comparisons were removed, as were SLAs where dairy farming had expanded or declined significantly. Two comparative cases were then selected for each of the four dairy farming SLAs, using those with greatest similarity as identified by the cluster analysis. ${ }^{2}$

When comparison regions were analysed, geographically proximate SLAs had quite different trends in rural population to the dairy farming SLAs, but similar to the time based and comparison to average analyses, these did not show consistent direction of variation. A similar result was obtained when specifically matched comparison regions were analysed: Moyne South and Corangamite South in general experienced less rural population decline than their comparison regions, while Corangamite North and Moyne North West experienced mostly greater rural population decline than their comparison regions (Table 2 ). This again was relatively uninformative for identifying how dairy farming contributed to macro-scale social change. Additional analysis of other influences contributing to population change in both the comparison regions and case study regions was not attempted due to the high level of resources needed for this type of analysis, an issue likely to occur in many SIAs and hence to limit usefulness of this approach.

\subsection{Scaling up model}

Comparative analyses on their own were relatively uninformative for identifying links between dairy farming and rural population

\footnotetext{
2 The comparison cases were the SLAs of Manjimup and Plantagenet (Corangamite North), Moora and Central Coast Pt B (Corangamite South), Denmark and Dardanup Pt B (Moyne South), and Cuballing and Kojonup (Moyne North West).
} 
change, unless accompanied by some kind of analysis of factors other than dairy farming likely to be influencing rural population trends. The scaling up model was trialled as an alternative approach that more explicitly incorporates the relative contribution of dairy farming versus other influences to change. As shown in Fig. 1, analysis involved three steps: analysing micro-scale impacts, scaling these up to the macro-scale, and identifying the relative contribution of dairy farming versus other influences to macro-scale social change.

\subsubsection{Identification of micro-scale impacts}

At the micro-scale, the goal of the scaling up approach is to identify the various types of social change that may accompany an impacting event, and when and why different individual outcomes may occur. In this study, the micro-scale was defined as the scale of the individual dairy farm or, in the case of businesses connected to dairy farming, the scale of the individual business. Focus group participants with expert knowledge of the dairy industry (five dairy farmers, two workers in businesses supplying goods and services to the dairy industry, and two government extension agents providing advice to dairy farmers) were asked to describe how a typical dairy farm had changed over 1991 to 2006, an important step in identifying how the impacting event - change in dairy farming - affected population numbers at the farm or individual business scale.

These experts identified that the typical dairy farm had become larger over time, with the farm manager adopting new milking technologies to enable them to manage a larger herd size. Expansion of herd size occurred through either intensifying grazing on existing land, or purchasing new land, usually previously used for dairy farming, beef grazing or sometimes sheep grazing. Many dairy farmers had difficulty hiring sufficient farm hands due to lack of available local labour. This provided additional incentive to improve labour efficiency on the farm; as a result, even when farm herd size increased employee numbers often remained steady or declined, depending on the extent to which adoption of new farming practices increased labour efficiency. The farmer used more fertiliser and contracted out more agricultural activities over time. Demographic characteristics of dairy farmers were not described as changing substantially, although some suggested that dairy farmers were younger than other farmers on average. Increased expenditure and use of contractors by dairy farmers were associated with growth in employment in businesses supplying goods and services to these farmers. In the dairy manufacturing sector, which in 2006 generated up to $18 \%$ of dairy industry employment in the four SLAs, the volume of production increased over time, as did efficiency of production.

How would these changes affect rural population levels at the farm scale or, in the case of suppliers and manufacturers, the individual business scale? A simple relationship was hypothesised: growth in employment was assumed to support population growth, and vice versa. While the linkages between employment and population change are more complex than this simple relationship suggests, with factors such as availability of alternative employment and workers' attachment to place influencing the relationship between employment and population growth, there is reasonable evidence supporting this hypothesis in rural Australia (Stimson et al., 2003; Maude, 2004).

Understanding likely change in population at the micro-scale therefore required identifying the net change in employment on individual farms and in businesses resulting from the changes described above. Net change in jobs depended on how dairy farms grew their herd size over time. Intensification of dairy farming through increasing stocking rates was not typically associated with growth in employment, as intensification was facilitated by adoption of new technologies that reduced labour requirements, rather than by expansion of employment. This suggests a neutral or negative impact on rural population levels. Where dairy farming expansion occurred through converting land previously used for another purpose to dairy farming, overall employment might grow. Schirmer et al. (2008a) found that dairy farming employed an average of 1.4 people per hectare in 2006 in the study region compared to $0.22-0.33$ per hectare for beef or sheep grazing (typical land uses prior to conversion to dairy farming), up to the farm gate. This suggests that dairy herd expansion occurring via conversion of land would result in a net increase in employment generated on the land, and hence lead to growth in rural population.

Based on micro-scale analysis, change in dairy farming may have a range of impacts on rural population levels, depending on the mechanisms by which it occurs. Identifying which of these is most influential, and hence the aggregate impact of change in dairy farming on rural population at the SLA scale in the absence of other influences, requires scaling up the analysis.

\subsubsection{Identification of macro-scale impacts in the absence of other social change}

The second step of the 'scaling up' approach involves predicting the macro-scale effects of the impacting event in the absence of other influences. In this case, that meant identifying the impact of change in dairy farming on rural population levels, assuming all else remained equal. To do this, the net change in dairy farming employment relative to changes in herd size and production was examined (Fig. 4). Data are shown for the region as a whole, as not all information was available at SLA scale. Overall, labour productivity growth outweighed growth in employment, with dairy farming employment growing more slowly than herd size over 1991 to 1996; falling by $13.7 \%$ over 1996 to 2001, the period when the most rapid expansion of the region's dairy herd was occurring; and declining more rapidly than cow numbers over 2001 to 2006. Overall labour requirements fell from 2.14 people per 100 cows in 1991 to 1.31 in 2006.

This suggests that the varying trends occurring on individual farms resulted in net growth in employment over 1991 to 1996 at the macro-scale of the SLA. In the absence of other influences, this would result in some growth in rural population. Over 1996 to 2001, growth in the dairy herd was associated with decline in employment and hence most likely with decline in rural population, with labour efficiency gains leading to loss of 858 jobs in dairy farming, and a net loss of 560 jobs in the industry as a whole once growth of 298 jobs in the manufacturing sector is accounted for. Similarly in 2001 to 2006 dairy farming change was most likely associated with population decline, as herd size fell slightly, and employment fell in both dairy farming and manufacturing.

In the absence of other changes, then, labour efficiency gains in two of the three periods studied outweighed employment growth generated by conversion of sheep and beef cattle grazing land to dairy farming, and population decline would most likely have accompanied dairy farming expansion during 1996 to 2006.

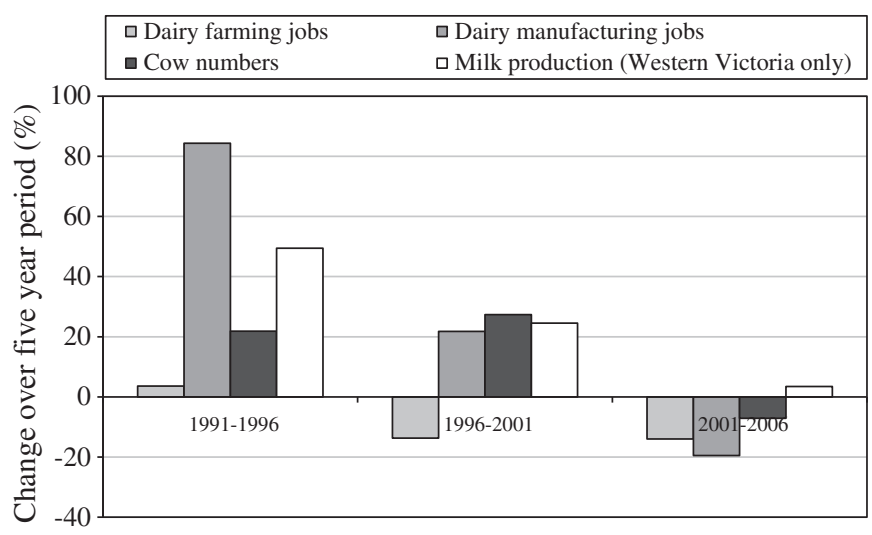

Fig. 4. Change in dairy herd size, employment and milk production, 1991 to 2006. 
3.4.3. Identifying the influence of dairy farming change versus other factors on macro-scale population change

Having identified that if all other influences remained stable, dairy farming expansion was likely associated with rural population growth during 1991 to 1996, and rural population decline during 1996 to 2006, the final step in the scaling up model is identifying the relative contribution of dairy farming versus other influences on rural population change.

First, the extent of dependence different SLAs had on dairy farming employment was examined, to help identify the extent to which change in dairy farming had potential to influence overall rural population trends. In 2006, the dairy industry directly generated $14.5 \%$ of all jobs in Corangamite North, 39.8\% in Corangamite South, 21.3\% in Moyne South and 11.6\% in Moyne North West. In all four SLAs, the proportion of jobs generated by the dairy industry was higher in earlier years, having declined over 1996 to 2006 by between $5 \%$ and $15 \%$. Change in the dairy industry therefore was likely to have a larger impact on rural population levels in Corangamite South, and to a lesser extent Moyne South, than the other two SLAs.

Second, change in dairy industry employment was compared to change in rural population. Fig. 5 shows change in dairy industry jobs in individual five year periods, ordered by the rate of rural population change. As some focus group participants felt dairy industry employment data were inaccurate for 1991, data for this period were not included in the analysis. In several of the five year periods, rural population declined at a greater rate when dairy industry jobs declined at a higher rate. There were, however, two exceptions, which were the main confounding factors in the earlier time series comparisons: during 2001 to 2006 Moyne South and Corangamite South both experienced relatively low rural population decline despite substantial decline in dairy industry jobs. As with the comparative analyses, explaining this trend required identifying factors influencing rural population trends other than change in dairy farming. Whereas the comparative approaches do not explicitly incorporate a requirement to undertake this type of analysis, it is an explicit and key part of the scaling up framework.

Focus group participants were asked to identify the different factors likely to influence population change in these SLAs, and these were then analysed to see if they, together with change in dairy farming, explained the trends seen in the data. Focus group participants identified that over 2001 to 2006 both Moyne South and Corangamite South experienced a substantial influx of 'seachangers': people shifting from cities to live on rural properties near the coast. This was believed to explain the higher than expected population growth in these SLAs. While specific statistics on 'seachangers' were not available, data on the proportion of new residents shifting from outside the SLAs to live in Moyne South and Corangamite South do support this theory: in Moyne South, 23.3\% of

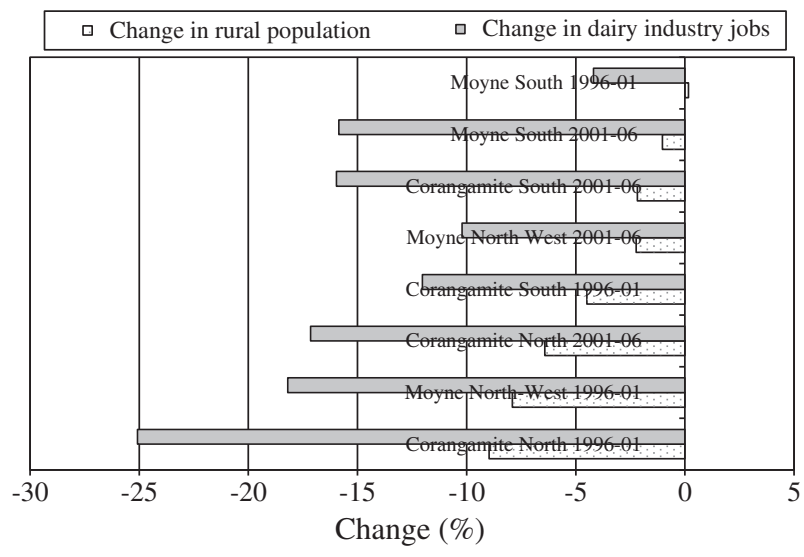

Fig. 5. Change in dairy industry employment and rural population, 1996 to 2006 . the population resident in 2006 had shifted from elsewhere to live in the SLA during 2001 to 2006, an increase from 20.3\% over 1996 to 2001; while in Corangamite South $18.5 \%$ of residents shifted to the SLA in the five years to 2006 compared to $14.4 \%$ over 1996 to 2001.

In addition, focus group participants suggested that decline in agricultural employment other than dairy farming jobs contributed to population decline in Moyne North West and Corangamite North over 1996 to 2006. To identify whether this might explain the higher than average decline observed in rural population in these SLAs, change in agricultural employment other than that generated by dairy farming was analysed. The number of people employed in agriculture other than dairy farming grew consistently during 1996 to 2006 in Corangamite North (by 3.6\% in total), Corangamite South (3.0\%), and Moyne South (22.2\%). In Moyne North West agricultural employment did decline, but only by $2.6 \%$, compared to a $35.4 \%$ decline in dairy farming employment. Therefore change in agricultural jobs outside the dairy farming sector was not a major influence on rural population change.

The combined effects of in-migration of new population seeking a lifestyle or 'seachange', and change in dairy farming employment, appear to explain much of the variation in population change observed in the four SLAs. While other factors no doubt also contributed to rural population change, this analysis does highlight the likely role of change in dairy farming, with decline in dairy industry jobs associated with more rapid rural population decline.

\subsubsection{Social impacts of changes to dairy farming and rural population}

Focus group participants were also asked to discuss the social impacts of changes to rural population resulting from dairy farming. Most described these as positive, based on their belief that rural population had grown, or declined less rapidly, as a result of growth in the dairy industry. Rural population growth was described as supporting local demand for goods and services, and supporting membership of local clubs and societies, all of which helped maintain positive social capital in the community.

\section{Discussion}

The results of the case study highlight a number of limitations of using comparative approaches to identify macro-scale social changes resulting from an impacting event. These comparative methods all have a common underlying logic: that identifying the consequences of an impacting event requires comparing social change processes in regions or at times where the event did not occur, to those where it did. Ideally, the only difference between the times or regions compared should be the impacting event.

In reality, it is difficult to find comparative cases where most factors other than the impacting event remain stable. This is evident in the case study results. Even when specifically matched comparison regions were utilised, no consistent pattern of change associated with change in dairy farming could be identified. However, this is not simply because cases were not adequately 'matched'. It also reflects the limited contribution of dairy farming change to change in macroscale population trends. This highlights an important issue when assessing macro-scale social impacts: the impacting event may be a relatively minor contributor to macro-scale trends, with other social change processes having a much larger impact. The extent to which an impacting event's influence is observable will depend on its scale relative to other social change processes. To overcome this, comparative cases ideally need to be matched based on both the nature and scale of social change processes, or the analysis needs to otherwise control for other influencing factors.

The challenges highlighted here are not unexpected: they are common to any research that uses small samples and in which the independent variable being studied is one of many influencing the outcome variable of interest. In SIA, where the number of cases 
available to study is often limited, they are particularly problematic. There is real danger of making false causal inferences, particularly if analysing only one or two cases, as is evident from the large variance in trends observed in the four dairy farming cases examined in this study. While increasing the number of cases analysed could address this problem, this is often impractical when undertaking SIA for two reasons: a large number of cases may not exist for comparison, and resources are often too limited to identify and analyse large numbers of comparative cases.

Given that small numbers of cases are generally available, an indepth explanatory approach is preferable to a quasi-quantitative approach that has limited emphasis on explanation. The scaling up approach utilises many aspects of time and geographic comparison methods, in particular through incorporating time-series comparisons, but addresses their limitations in two ways: by developing a chain of logic that links change at the local scale to change at the macro-scale, enabling identification of the mechanisms by which the impacting event may contribute to macro-scale change; and by identifying factors other than the impacting event influencing social change processes.

In some ways, the scaling up approach is similar to concepts of baseline analysis, in that it explicitly identifies other social trends occurring in a community and attempts to separate their effects from that of the impacting event. However, it differs in its focus on identifying the ultimate contribution of each to change in the variable of interest (in this case, population change); and on breaking a region into multiple cases of change to enable identification of how this varies in different circumstances. This explicitly acknowledges that an impacting event may be a relatively minor factor influencing social change, rather than assuming that it is the major influence on change. While modifying comparative approaches to better incorporate analysis of the multiple factors influencing social change is an alternative to using the scaling-up framework, the scaling-up framework has the benefit of making more explicit links between the micro- and macro-scales than occurs in comparative analyses relying on macro-scale data. This enables an improved understanding of how the varying actions taken at micro-scale, some of which may lead to quite different and contradictory types of social changes, aggregate to influence macro-scale trends.

Using the scaling up model successfully overcame many of the limitations of comparative analysis. The likely effects of change to dairy farming on rural population could be identified, as well as their relative contribution to change in rural population observed at the macro-scale. Identifying the extent of contribution of the impacting event enables identification of where and when mitigating strategies may be most needed. In this study, decline in rural population resulting from growing labour efficiency in the dairy industry was offset in two regions by growth in rural population associated with the 'seachange' phenomenon, while in other two regions it was not. Any strategies aimed at mitigating impacts of change in dairy farming on rural population would be better targeted at the regions where dairy farming has a greater overall impact on rural population, as these are the regions where the greatest negative social impacts are likely to occur.

The scaling up approach uses a combination of technocratic and participatory approaches to assessment. This presents both opportunities and challenges. Using independent data to verify and challenge perceptions of local residents provides a useful discussion point for stakeholders involved in an SIA process, particularly where conflicting views exist about the consequences of an impacting event. Some limitations of purely technocratic assessment can be addressed through analysing statistical data using participatory methods, with local residents able to analyse data based on in-depth local knowledge. However, despite local residents strongly predicting that change in dairy farming was likely to lead to rural population growth, the opposite trend was in fact identified. This presented a challenge: perceptions of social change were not supported by the macro-scale analysis, yet residents reported positive experiences of social impact based on these perceptions. This highlights the importance of understanding how perceptions of social change processes influence the experience of social impact, something that was not explored further in this study.

The scaling up approach was examined here through an ex-post study. It could also be used as part of ex-ante SIA. The main challenges with ex-ante analysis are likely to be identifying the nature of local scale social change resulting from the impacting event, with results of the case study suggesting local residents' perceptions did not always reflect the changes that occurred; and identifying all possible influences on social change and their likely contribution relative to the impacting event. Developing a range of scenarios is likely to be the most useful approach to overcoming these limitations, particularly given the high uncertainty involved in attempting to predict the direction and nature of influences other than the impacting event.

The scaling up approach has limitations. There is a risk of false causal inference if all factors contributing to macro-scale social change are not identified, particularly given the small numbers of cases involved. Breaking a region into multiple cases that can be compared has the advantage of better identifying the differences in macroscale impacts in varying contexts, but may be problematic where spatial linkages between the location of the impacting event and the human communities it impacts are large. Integration of the scaling up model and methods such as Town Resource Cluster analysis (Fenton et al., 2003) may help overcome this.

Despite these limitations, the results of this study show that the scaling up model can overcome some of the problems of common comparative approaches, and enable a more problematised assessment of the role of an impacting event in contributing to macro-scale social change.

\section{Conclusions}

Assessing the macro-scale social changes resulting from an impacting event is an important dimension of SIA. The scaling up model proposed in this paper moves beyond previous approaches to assessing macro-scale change in two important ways: it links microscale and macro-scale change, and identifies the relative contribution of the impacting event versus other influences to macro-scale social change. It can be used in combination with the comparative approaches recommended in the literature, which were relatively uninformative when applied on their own in the case study presented in this paper. The scaling up model allows the SIA practitioner to identify when and to what extent an impacting event leads to macroscale change. This in turn enables better targeting of mitigation strategies aimed at reducing negative social impacts occurring at the macro-scale, as they can be directed towards those communities where the impacting event will have the greatest influence.

\section{Acknowledgments}

The case study reported in this paper formed part of the work undertaken for the Land Use Change study, hosted by the Cooperative Research Centre for Forestry and funded by a consortium of 11 organisations. The funding and support of these organisations is gratefully acknowledged. I also thank two reviewers for their thoughtful and detailed comments on the manuscript.

\section{References}

Adger WN. Social and ecological resilience: are they related? Progress in Human Geography 2000;24(3):347-64.

Asselin J, Parkins JR. Comparative case study as SIA: possibilities and limitations for anticipating social change in the far north. Soc Indic Res 2009;94:483-97. 
Becker DR, Harris CC, Nielsen EA, McLaughlin WJ. A comparison of a technical and a participatory application of social impact assessment. Impact Assess Project Apprais 2004;22:177-89.

Brooks N, Adger WN. Assessing and enhancing adaptive capacity. In: Lim B, SpangerSiegfried E, editors. Adaptation policy frameworks for climate change: developing strategies, policies and measures. Cambridge: Cambridge University Press; 2004. p. $167-81$.

Brown VA, Ritchie J. Sustainable communities: what should our priorities be? Health Promot J Aus 2006;17:211-6.

Burdge RJ. The social impact assessment model and the planning process. Environ Impact Assess Rev 1987; 7:141-50.

Burdge RJ. Social impact assessment and the planning process. In: Burdge RJ, editor. The concepts, process and methods of social impact assessment. Middleton: Social Ecology Press; 2004. p. 31-40.

Burdge RJ, Johnson S. The comparative social impact assessment model. In: Burdge RJ, editor. The concepts, process and methods of social impact assessment. Middleton: Social Ecology Press; 2004. p. 15-29.

Bureau of Rural Sciences. Socio-economic impact assessment toolkit: a guide to assessing the socio-economic impacts of marine protected areas in Australia. Canberra: Commonwealth of Australia; 2005.

Fenton M, Coakes S, Marshall N. Vulnerability and capacity measurement. In: Becker HA, Vanclay F, editors. The international handbook of social impact assessment. Cheltenham: Edward Elgar; 2003. p. 211-30.

Fortin MJ, Gagnon C. An assessment of social impacts of national parks on communities in Quebec, Canada. Environ Conserv 1999;6:200-11.

Gallopin GC. Linkages between vulnerability, resilience, and adaptive capacity. Global Environ Change 2006;6:293-303.

Geddes B. How the cases you choose affect the answers you get: selection bias in comparative politics. Polit Anal 1990;2:131-50.

Hugo G. The state of rural population. In: Cocklin C, Dibden J, editors. Sustainability and change in rural Australia. Sydney: UNSW Press; 2005. p. 56-79.

Indhapanya C, Routray JK, Kammeier HD. Spatial analysis of social impacts of the Eastern Seaboard Development Programme, Thailand. Impact Assess Project Apprais 1999;17:203-16.

Maude A. Regional development processes and policies in Australia: a review of research 1990-2002. Eur Plann Stud 2004;12:3-26.

Pelling M, High C. Understanding adaptation: what can social capital offer assessments of adaptive capacity? Global Environ Change 2005;15:308-19.

Petajarjarvi R. Follow up of socio-economic aspects in a road project in Finland. Impact Assess Project Apprais 2005;27:95-110.

Ross H, McGee TK. Conceptual frameworks for SIA revisited: a cumulative effects study on lead contamination and economic change. Impact Assess Project Apprais 2006;24:139-49.

Schirmer J, Williams K, Dunn C. Preliminary summary of findings of the land use change project. Hobart: CRC for Forestry; 2008a.

Schirmer J, Williams K, Borschmann P, Dunn C. Living with land use change: different views and perspectives. Hobart: CRC for Forestry; 2008b.
Slootweg R, Vanclay F, van Schooten M. Function evaluation as a framework for the integration of social and environmental impact assessment. Impact Assess Project Apprais 2001;19:19-28.

Smit B, Wandel J. Adaptation, adaptive capacity and vulnerability. Global Environ Change 2006;15:282-92.

Stimson R, Baum S, O'Connor K. The social and economic performance of Australia's large region cities and towns: implications for rural and regional policy. Aust Geogr Stud 2003:41:131-47.

Taylor N, Goodrich C, Fitzgerald G, McClintock W. Undertaking longitudinal research. In: Becker HA, Vanclay F, editors. The international handbook of social impact assessment. Cheltenham: Edward Elgar; 2003. p. 13-25.

Taylor CM, Bryan CH, Goodrich CG. Social assessment: theory, process and techniques. 3rd ed. Middleton: Social Ecology Press; 2004.

Teigland J. Predictions and realities: impacts on tourism and recreation from hydropower and major road developments. Impact Assess Project Apprais 1999;17:67-76.

The Interorganizational Committee on Principles and Guidelines for Social Impact Assessment. Principles and guidelines for social impact assessment in the USA Impact Assess Project Apprais 2003;21:231-50.

Twigg J. Social impact assessment: tools for mainstreaming disaster risk reduction guidance note 11. Switzerland: Red Cross and Red Crescent Societies and the ProVention Consortium; 2007.

van Schooten M, Vanclay F, Slootweg R. Conceptualizing social change processes and social impacts. In: Becker HA, Vanclay F, editors. The international handbook of social impact assessment. Cheltenham: Edward Elgar; 2003. p. 74-91.

Vanclay F. Conceptualising social impacts. Environ Impact Assess Rev 2002;22: 183-211.

Vanclay F. International principles for social impact assessment. Impact Assess Project Apprais 2003;21:5-12.

Williams K, Dunn C, Ford R, Anderson N. Understanding residents' views on land use change. Hobart: CRC for Forestry; 2008

Wolf CP. Social impact assessment: a methodological overview. In: Finterbusch K, Llewellyn LG, Wolf CP, editors. Social impact assessment methods. Beverly Hills: Sage; 1983. p. 15-33.

Woodside Energy Ltd.. Pluto LNG development Burrup LNG Park Social Impact Study. Woodside Energy, March 2007. URL:http://www.woodside.com.au/NR/rdonlyres/ 32EA213B-D3E6-46DE-BF97-0A015CB00694/0/Pluto_LNG_Development_Burrup_ LNG_Park_Social_Impact_Study_June_2007.pdf2007 Accessed July 10th 2010.

Yohe G, Tol RSJ. Indicators for social and economic coping capacity - moving toward a working definition of adaptive capacity. Global Environ Change 2002;12:25-40.

Jacki Schirmer has been undertaking research on social dimensions of natural resource management for 10 years. After working as a social scientist assessing social impacts of changing access to natural resources for the Australian government, from 2005 she has worked as a research fellow at the Australian National University. Her research interests are primarily focused on understanding socio-economic impacts of changes in land use and access to natural resources. 